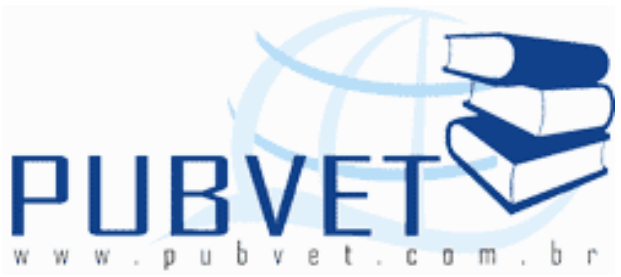

PUBVET, Publicações em Medicina Veterinária e Zootecnia.

\title{
Efeito da irrigação e da adubação nitrogenada no teor de proteína bruta do Capim-Elefante (Pennisetum purpureum cv. Pioneiro)
}

Braz Henrique Nunes Rodrigues ${ }^{1}$, João Avelar Magalhães ${ }^{2}$, Alex Carvalho Andrade $^{3}$, Maria Socorro de Souza Carneiro ${ }^{4}$, Newton de Lucena Costa ${ }^{5}$, Francisco José de Seixas Santos ${ }^{6}$, Eduardo Esmeraldo Augusto Bezerra ${ }^{7}$

${ }^{1}$ Eng. Agrícola, M.Sc., Pesquisador da Embrapa Meio-Norte. Doutorando em Irrigação, UFCG. Campina Grande, Paraiba.

${ }^{2}$ Médico Veterinário, D.Sc., Embrapa Meio-Norte. Parnaíba, Piauí.

${ }^{3}$ Zootecnista, D.Sc., Professor da UESPI. Parnaíba, Piauí.

4 Eng. Agrônomo, D.Sc., Professora do Departamento de Zootecnia, UFC. Fortaleza, Ceará.

5 Eng. Agrônomo, M.Sc., Embrapa Roraima. Doutorando em Agronomia/Produção Vegetal, UFPR. Curitiba, Paraná.

${ }^{6}$ Eng. Agrônomo, D.Sc., Pesquisador da Embrapa Meio-Norte.

${ }^{7}$ Médico Veterinário, M.Sc., Ematerpi. Parnaíba, Piauí.

\section{Resumo}

O objetivo deste trabalho foi avaliar o efeito de diferentes níveis de irrigação e de adubação nitrogenada sobre o teor de proteína bruta (\%PB) da gramínea forrageira Pennisetum purpureum cv. Pioneiro. O trabalho foi conduzido na área experimental da Embrapa Meio-Norte em Parnaíba, Piauí, em Neossolo Quartzarênico Órtico Típico. Os níveis de irrigação aplicados foram calculados 
em função do fracionamento da evaporação do tanque classe " $A$ " (ECA) entre duas irrigações consecutivas: 0,$2 ; 0,6$ e 1,0. Os tratamentos de adubação foram 100, 200 e $300 \mathrm{~kg} / \mathrm{ha}$.ano de $\mathrm{N}$ aplicados na forma de uréia. Para efeito de análise, foram processados cinco cortes da gramínea no período de avaliação. O aumento das lâminas de irrigação não apresentou efeito significativo nos teores de proteína bruta do capim-pioneiro. O efeito da adubação nitrogenada sobre o teor de proteína bruta do capim-pioneiro foi linear. A combinação da lâmina de água correspondente a 0,2 ECA e o nível de adubação de $300 \mathrm{~kg} / \mathrm{ha}$.ano de $\mathrm{N}$ apresenta os melhores resultados, em função da \%PB encontrada e da possibilidade de economia de água, com redução nos custos de produção da forragem.

Termos para indexação: pastagem irrigada, lâmina de irrigação, nutrição.

\title{
Effect of irrigation and nitrogen fertilization on crude protein content of Elephantgrass (Pennisetum purpureum var. Pioneiro)
}

\begin{abstract}
The objective of this work was evaluate the effect of different irrigation levels and nitrogen fertilization on the crude protein content (\%PB) of forage grass Pennisetum purpureum cv. Pioneiro. The work was carried at Embrapa MeioNorte Experimental Area in Parnaíba, Piauí State,Brazil. The irrigation depths were applied as a function of Class " $A$ " pan evaporation fractions (ECA) (0.2, 0.6 and 1.0). The nutrient levels used were 100,200 and $300 \mathrm{~kg} / \mathrm{ha}$ of $\mathrm{N}$ (urea) broadcast applied. During the evaluation period, five cuts were taken. The increase of the irrigation sheets didn't present significant effect on the $\% P B$ of the grass, but the effect of the nitrogen fertilization was linear. The irrigation depths corresponding to 0.2 ECA and level of fertilization of 300 $\mathrm{kg} / \mathrm{ha}$ of $\mathrm{N}$ presented the best combination, in function of the \%PB ones and the possibility of economy of water, with reduction in the costs of production of the forage.
\end{abstract}

Index terms: irrigated grassland, irrigation levels, nutrition. 
RODRIGUES, B.H.N. et al. Efeito da irrigação e da adubação nitrogenada no teor de proteína bruta do Capim-Elefante (Pennisetum purpureum cv. Pioneiro). PUBVET, Londrina, V. 5, N. 4, Ed. 151, Art. 1015, 2011.

\section{Introdução}

Na Região Nordeste, e em especial no Meio-Norte do Brasil, a produção de leite exibe índices de produtividade muito baixos, com uma grande variação nos níveis de tecnologia utilizados. A alimentação das vacas em lactação é feita à base de concentrados de alto custo e as pastagens formadas são, em geral, de baixa qualidade e incorretamente manejadas (MAGALHÃES et al., 2003). Uma alternativa para o incremento da atividade na região é a utilização de gramíneas forrageiras de alto potencial produtivo em pastejo rotativo, como forma de proporcionar uma boa qualidade de forragem para as vacas em lactação, com reflexos positivos na produtividade dos animais e na redução dos custos de produção de leite (ASSIS, 1997; VILELA; ALVIM, 1996).

A avaliação de plantas forrageiras, visando a seleção de espécies é fundamental, principalmente, ao se considerar que a produtividade e o valor nutritivo de uma pastagem dependem muito do manejo adotado, sofrendo grande influência das condições ambientais.

Até recentemente, a inexistência de cultivares de capim-elefante, específicas para uso sob pastejo, era considerada uma dificuldade à expansão de novas áreas de pastagem com esta forrageira. A cultivar Pioneiro foi desenvolvida e recomendada pela Embrapa, inicialmente, para as condições edafoclimáticas da região norte de Minas Gerais (PEREIRA et al., 1997). Devido às boas características de produção e valor nutritivo da cultivar naquelas condições, tem-se expandido as fronteiras regionais de sua utilização em pastagens rotativas, sugerindo, no entanto, maiores avaliações antes do cultivo em maior escala.

Assim, o objetivo deste trabalho foi avaliar o efeito de diferentes níveis de irrigação e de adubação nitrogenada sobre o teor de proteína bruta (\%PB) da gramínea Pennisetum purpureum cv. Pioneiro, em solos de Tabuleiros Costeiros do Piauí. 
RODRIGUES, B.H.N. et al. Efeito da irrigação e da adubação nitrogenada no teor de proteína bruta do Capim-Elefante (Pennisetum purpureum cv. Pioneiro). PUBVET, Londrina, V. 5, N. 4, Ed. 151, Art. 1015, 2011.

\section{Material e Métodos}

O trabalho foi conduzido na área experimental da Embrapa Meio-Norte, em Parnaíba-PI ( $3^{\circ} 5^{\prime} \mathrm{S}, 41^{\circ} 47^{\prime} \mathrm{W}$ e altitude de 46,8 m), em um Neossolo Quartzarênico Órtico Típico, (Tabela 1), durante o ano de 2001.

Tabela 1. Características físico-químicas do solo da área experimental.

\begin{tabular}{ccc}
\hline Características & Unidade & Valor \\
\hline Areia & $\mathrm{g} \cdot \mathrm{kg}^{-1}$ & 865 \\
Silte & $\mathrm{g} \cdot \mathrm{kg}^{-1}$ & 39 \\
Argila & $\mathrm{g} \cdot \mathrm{kg}^{-1}$ & 96 \\
$\mathrm{pH}$ em água $(1: 2,5)$ & & 5,98 \\
$\mathrm{P}$ & $\mathrm{mg} \cdot \mathrm{dm}^{-3}$ & 15,43 \\
$\mathrm{~K}$ & $\mathrm{mmol} \cdot \mathrm{dm}^{-3}$ & 2,4 \\
$\mathrm{Ca}$ & $\mathrm{mmol} \cdot \mathrm{dm}^{-3}$ & 16,0 \\
$\mathrm{Mg}$ & $\mathrm{mmol}_{\mathrm{c}} \cdot \mathrm{dm}^{-3}$ & 7,0 \\
$\mathrm{Al}$ & $\mathrm{mmol}_{\mathrm{c}} \cdot \mathrm{dm}^{-3}$ & 0,0 \\
\hline
\end{tabular}

Fonte: Laboratório de Solos - Embrapa Meio-Norte.

Os dados referem-se à camada de $0-20 \mathrm{~cm}$

O delineamento experimental utilizado foi o de blocos casualizados com parcelas subdivididas e três repetições. Nas parcelas foram distribuídas as lâminas e nas sub-parcelas os níveis de adubação. A gramínea Pennisetum purpureum cv. Pioneiro, foi plantada em parcelas experimentais de 2,4 $\mathrm{m} \times 3,0$ $\mathrm{m}$, definindo-se a área central de $0,5 \mathrm{~m} \times 1,0 \mathrm{~m}$ como área útil para coleta do material vegetativo destinado às análises de proteína bruta (\%PB) da forragem.

Para efeito de aplicação dos tratamentos, adotou-se o sistema de gotejamento com um turno de irrigação de dois dias. Os níveis de lâminas de água aplicados foram calculados em função do fracionamento da evaporação do tanque classe " $A$ " (ECA) entre duas irrigações consecutivas: 0,2; 0,6 e 1,0 ( $L 1, L 2$ e $L 3$ respectivamente).

As doses de $\mathrm{N}$ avaliadas foram: 100, 200 e $300 \mathrm{~kg} / \mathrm{ha}$.ano, na forma de uréia. Aplicou-se, em fundação, de maneira uniforme em todas as parcelas, $100 \mathrm{~kg} / \mathrm{ha}$ de $\mathrm{P}_{2} \mathrm{O}_{5}$ e $50 \mathrm{~kg} / \mathrm{ha}$ de $\mathrm{K}_{2} \mathrm{O}$, nas formas de superfosfato simples e cloreto de potássio, respectivamente. Os níveis de nitrogênio constituíram os 
tratamentos de adubação e foram aplicados em cobertura, manualmente. A gramínea, que já havia sido implantada no ano anterior, recebeu quatro cortes de uniformização durante o período das chuvas (jan a jun/2001) e um último corte de uniformização no início do período de estiagem (jul/2001), quando se iniciaram os tratamentos de irrigação e ocorreu a aplicação dos níveis de $\mathrm{N}$ em cobertura. A primeira amostragem ocorreu 28 dias após este corte de uniformização e as demais se procederam, também, em intervalos de 28 dias, totalizando cinco cortes no período.

Os valores de proteína bruta (\%PB) foram determinados pelo método de Kjeldahl, conforme descrito por SILVA (1990). As análises estatísticas foram realizadas utilizando-se o Statistical Analysis System (SAS INSTITUTE, 1989).

\section{Resultados e Discussão}

A Tabela 2 apresenta os valores médios de proteína bruta (\%PB) da gramínea sob o efeito dos três níveis de água aplicados e dos três níveis de adubação nitrogenada, referentes aos cinco cortes de avaliação efetuados no período.

Tabela 2. Valores médios de proteína bruta (\%PB) da gramínea Pennisetum purpureum cv. Pioneiro, em função de três lâminas de água (L), associadas a três níveis de nitrogênio (N). Parnaíba-PI,2001

\begin{tabular}{cccc} 
& N1 & N2 & N3 \\
\hline L1 & 14,96 & 15,39 & 17,65 \\
L2 & 15,22 & 14,83 & 17,06 \\
L3 & 13,16 & 15,45 & 16,50
\end{tabular}

L1: $200 \mathrm{~mm}$; L2: $600 \mathrm{~mm}$; L3: $1000 \mathrm{~mm}$; N1: $100 \mathrm{~kg} / \mathrm{ha} ; \mathrm{N2}: 200 \mathrm{~kg} / \mathrm{ha}$; N3: $300 \mathrm{~kg} / \mathrm{ha}$

A análise da regressão revelou efeito linear para doses de $N(y=12,947$ $+0,031 x ; R^{2}=0,9477$ ), porém sem interação $L \times N$ (Figura 1). Os valores médios encontrados de \%PB para a cultivar Pioneiro, com destaque para a maior dose de $\mathrm{N}$, comprovam o valor nutritivo dessa forrageira para a produção de leite a pasto. $O$ efeito de doses crescentes de nitrogênio no 
RODRIGUES, B.H.N. et al. Efeito da irrigação e da adubação nitrogenada no teor de proteína bruta do Capim-Elefante (Pennisetum purpureum cv. Pioneiro). PUBVET, Londrina, V. 5, N. 4, Ed. 151, Art. 1015, 2011.

aumento dos teores de proteína bruta estão condizentes com os resultados apresentados por outros autores, quando da avaliação da adubação nitrogenada na qualidade do capim elefante. AGUIAR et al. (2002), utilizando doses crescentes de nitrogênio em capim elefante cultivado em um Neossolo, obtiveram médias de PB variando de 10,07 a 17,13\%, com doses de $\mathrm{N}$ variando entre 0 e $200 \mathrm{~kg} / \mathrm{ha}$.ano, respectivamente. SOARES et al. (1998) afirmaram ser $300 \mathrm{~kg} / \mathrm{ha}$.ano de $\mathrm{N}$ a dose mais adequada para a exploração do capim elefante sob pastejo. Efeitos lineares da adubação nitrogenada sob os teores de PB dos capins Panicum maximum cv. Mombaça, Andropogon gayanus e Brachiaria brizantha cv. Marandu foram reportados por Mochel Filho (2009) e Magalhães (2010), após trabalharem com estas gramíneas sob efeito de adubação com 200, 400, 600 e 800 kg/ha.ano nas mesmas condições ecológicas deste experimento.

O efeito da irrigação sobre o conteúdo de PB foi condizente com os resultados apresentados por Lopes et al. (2002), que concluíram ainda que a irrigação provocou queda nos teores de proteína com os maiores níveis de água aplicados. Esse fato certamente está associado com as mais altas taxas de crescimento observadas sob condições de irrigação, causando, com isso, uma diluição desse nutriente na forragem produzida, o que também foi observado por Botrel et al. (1991). Esses autores verificaram que as pastagens irrigadas sofreram uma redução de até $30 \%$ no teor médio de proteína bruta quando comparadas às não irrigadas. No entanto, através de uma análise das taxas de produção de matéria seca e do teor de PB das cultivares irrigadas e não-irrigadas, verificou-se que a irrigação proporcionou um aumento substancial na produção de PB. Essa análise é conveniente, principalmente nas condições climáticas do presente experimento, onde a irrigação é um insumo importante para a produção eficiente de forragem, visando a alimentação racional de vacas em lactação. 
RODRIGUES, B.H.N. et al. Efeito da irrigação e da adubação nitrogenada no teor de proteína bruta do Capim-Elefante (Pennisetum purpureum cv. Pioneiro). PUBVET, Londrina, V. 5, N. 4, Ed. 151, Art. 1015, 2011.

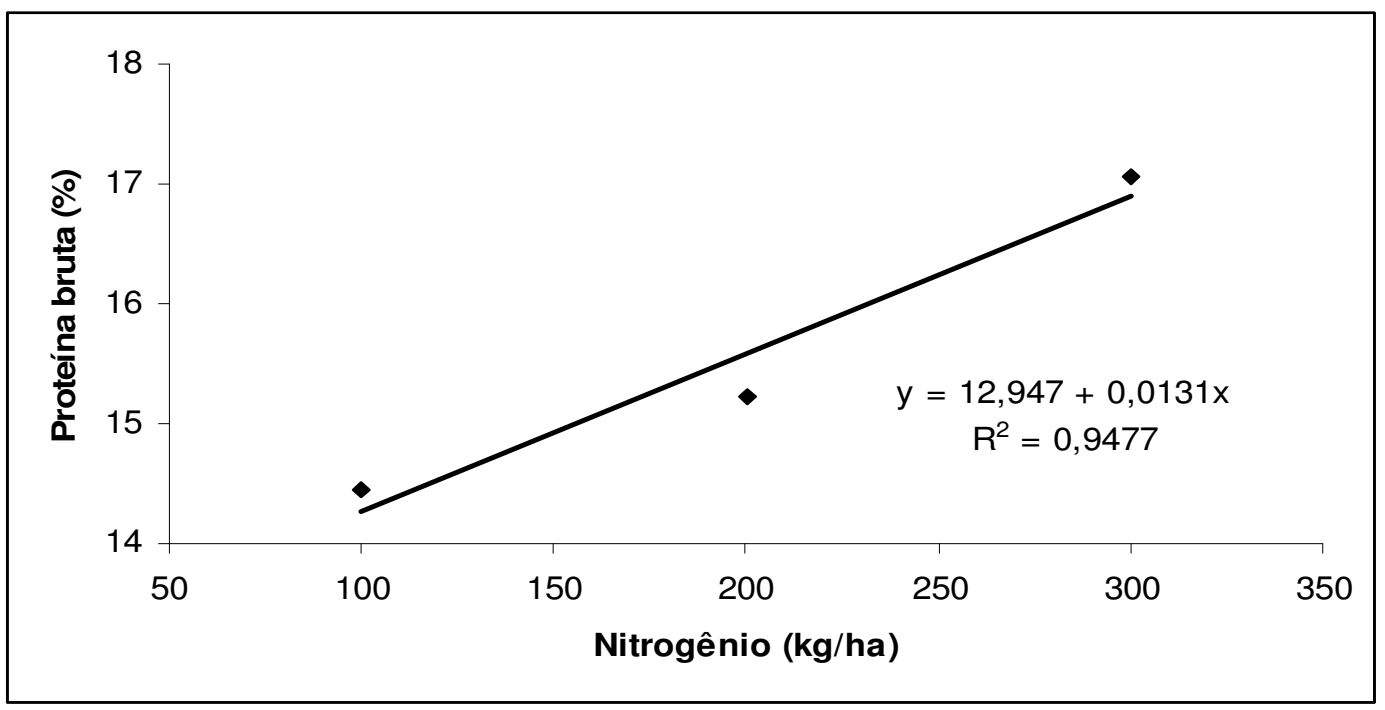

Figura 1. Efeito de doses de nitrogênio no teor de proteína bruta do capimpioneiro

\section{Conclusões}

Com o aumento das doses de nitrogênio há incrementos nos valores de proteína bruta do capim-pioneiro, ao mesmo tempo em que as lâminas de irrigação não influenciam estes valores.

Nas condições ecológicas dos Tabuleiros Costeiros do Piauí, a lâmina correspondente a 0,2 ECA e a dose de $300 \mathrm{~kg} / \mathrm{ha}$.ano de $\mathrm{N}$ apresentam a melhor combinação de irrigação e adubação, considerando a eficiência para a produção de proteína bruta e a possibilidade de economia de água.

\section{Referências Bibliográficas}

AGUIAR, E.M.; BEZERRA NETO, E.; DANTAS, J.A. Efeito da adubação nitrogenada na composição bromatológica do capim-elefante cV. Mott em dois tipos de solos. In: REUNIÃO ANUAL DA SOCIEDADE BRASILEIRA DE ZOOTECNIA, 39, 2002, Recife. Anais.... Recife: SBZ, 2002. 4p. (CD-ROM)

ASSIS, A.G. de. Produção de leite a pasto no Brasil. In: SIMPÓSIO INTERNACIONAL SOBRE PRODUÇÃO ANIMAL EM PASTEJO, 1997, Viçosa. Anais... Viçosa: UFV, 1997, p.381-409.

BOTREL, M.A., ALVIM, M.J., XAVIER, D.F. Efeito da irrigação sobre algumas características agronômicas de cultivares de capim-elefante. Pesquisa Agropecuária Brasileira, v.26, n.10, p.1731-1736. 1991. 
RODRIGUES, B.H.N. et al. Efeito da irrigação e da adubação nitrogenada no teor de proteína bruta do Capim-Elefante (Pennisetum purpureum cv. Pioneiro). PUBVET, Londrina, V. 5, N. 4, Ed. 151, Art. 1015, 2011.

LOPES, R. dos S.; FONSECA, D.M.; ANDRADE, A.C. et al. Disponibilidade de lâminas foliares e teores de proteína bruta, FDN e FDA em pastagens de capim-elefante submetidas a irrigação. In: REUNIÃO ANUAL DA SOCIEDADE BRASILEIRA DE ZOOTECNIA, 39, 2002, Recife. Anais... Recife: SBZ, 2002, 3p. (CD-ROM).

MAGALHÃES, J. A. Características morfogênicas e estruturais, produção de forragem e composição bromatológica de gramíneas forrageiras sob irrigação e adubação. Fortaleza: UFC, 2010. 130f. Tese (Doutorado em Zootecnia) - Universidade Federal do Ceará.

MAGALHÃES, J.A.; LOPES, E.A.; RODRIGUES, B.H.N. et al. A. Eficiência técnica de um sistema de produção com gado mestiço para bacias leiteiras dos estados do Piauí e Maranhão. Revista Agropecuária Catarinense, v. 16, n. 3, p. 30-32, 2003.

MOCHEL FILHO, W. de J.E. Fluxo de biomassa, produção de forragem e composição químico-bromatológica do capim-Mombaça sob adubação e irrigação. Fortaleza: UFC, 2009. 96f. Dissertação (Mestrado em Zootecnia) - Universidade Federal do Ceará.

PEREIRA, A.V.; MARTINS, C.A.; FILHO, A.B.C. et al. Pioneiro - nova cultivar de capim-elefante para pastejo. In: REUNIÃO ANUAL DA SOCIEDADE BRASILEIRA DE ZOOTECNIA, 34., 1997, Juiz de Fora. Anais... Juiz de Fora: SBZ, 1997, p.102-104.

SOARES, J.P.G.; PEREIRA, O.G.; AROEIRA, L.J.M. et al. Disponibilidade e composição química do capim-elefante (Pennisetum purpureum Shum.) sob pastejo, adubado com duas doses de nitrogênio. In: REUNIÃO ANUAL DA SOCIEDADE BRASILEIRA DE ZOOTECNIA, 35, 1998, Botucatu. Anais... Botucatu: SBZ, 1998, 3p. (CD-ROM).

SAS INSTITUTE. User's guide: version 6.4 ed. Cary, 1989. v.2, 846p.

SILVA, D. J. Análise de alimentos (métodos químicos e biológicos). 2 ed. Viçosa, UFV. Imprensa Universitária, 1990. 165p.

VILELA, D.; ALVIM. M.J. Produção de leite em pastagem de "coast-cross". In: WORKSHOP SOBRE O POTENCIAL FORRAGEIRO DO GÊNERO CYNODON, 1996, Juiz de Fora. Anais... Juiz de Fora: EMBRAPA-CNPGL, 1996, p.77-91. 